\title{
HETERONOMIA E IMPUTABILIDADE NA FUNDAMENTAÇÃO DA METAFÍSICA DOS COSTUMES
}

\author{
Aguinaldo Pavãol
}

RESUMO Pretendo discutir o modo como Kant relaciona os conceitos de liberdade e moralidade na FMC. Neste livro, Kant afirma que "vontade livre e vontade submetida a leis morais são uma e mesma coisa" (FMC III: $\S 2 / B A$ 98). Aparentemente apenas a vontade autônoma seria livre, não restando outra alternativa que não seja assimilar a vontade heterônoma à necessidade natural. Essa conseqüência provocaria certamente um embargo da imputabilidade das ações imorais. Quero defender que, embora Kant tenha obscurecido as distinções entre vontade livre e vontade moral, se nos ativermos à analise do conceito de vontade em FMC II: $\S 12$ (BA 36-37), poderemos defender que não apenas a autonomia, mas também a heteronomia é livremente escolhida, tornando inteligivel, assim, a imputabilidade dos atos imorais. Sustento, portanto, que é possivel, apesar das ambigüidades de Kant, pensar a imputabilidade moral a partir de recursos conceituais internos à Fundamentação. Desse modo, não será necessário invocar a distinção entre Wille $e$ Willkür desenvolvida na $\mathrm{MC}$, nem mesmo outras obras para dar conta deste problema.

ABSTRACT I intend to discuss the way as Kant relates the concepts of freedom and morality in the Foundations. In this book, Kant argues that" free will and will submitted to moral laws are one and same". Apparently just the autonomous will would be free, not remaining other alternative that

1 Professor de Filosofia UEL/PR. Mestre em Filosofia pela UFRGS e doutorando em Filsofia na UNICAMP.

KRITERION, Belo Horizonte, n 105, Jun/2002, p.119-135 
is not to assimilate the heteronomous will to the natural necessity. That consequence would provoke an embargo of the imputability of immoral actions. I want to defend that, although Kant has obscure the distinctions between free will and moral will, if we concentrate on analyzes of the concept of will in Foundations II, we can defend that not just the autonomy, but the heteronomy is also chosen freely, turning intelligible, like this, the imputability of immoral acts. I sustain, therefore, that it's possible, in spite of the ambiguities of Kant, to think the moral imputability starting from internal conceptual resources to Foundations. Thus, it won't be necessary to invoke the distinction between Wille and Willkür, not even other works to solve this problem.

Palavras-chave heteronomia, vontade, agir racional, liberdade, imputabilidade.

\section{Introdução}

Embora Kant não se ocupe de forma ostensiva com a imputabilidade moral, pode-se dizer que toda a sua reflexão moral gira em torno desta questão. Kant chega a afirmar que é "em vista da imputabilidade das ações" que a moral se apresenta "como fonte da filosofia crítica" ${ }^{2}$. Para tanto, é claro que o conceito de liberdade deve ser elucidado e justificado, pois sem a atribuição de liberdade ao homem não cabem juízos de imputação. Pretendo discutir, aqui, o modo como Kant relaciona os conceitos de liberdade e moralidade na $F M C$. Neste livro, Kant afirma que "vontade livre e vontade submetida a leis morais são uma e mesma coisa" (FMC III: § 2/BA 98). Aparentemente apenas a vontade autônoma seria livre, não restando outra alternativa que não seja assimilar a vontade heterônoma à necessidade natural. Essa conseqüência provocaria certamente um embargo da imputabilidade das ações imorais. Quero defender que, embora Kant tenha obscurecido as distinções entre vontade livre e vontade moral, se nos ativermos à analise do conceito de vontade em FMC II: $\S 12$ (BA 36-37), poderemos defender que não apenas a autonomia, mas também a heteronomia é livremente escolhida, tornando inteligível, assim, a imputabilidade dos atos imo-

2 Os Progressos da Metafísica, Ak 335. Adoto, de agora em diante, as seguintes abreviaturas das doras de Kant. CRP (Crítica da Razão Pura), FMC (Fundamentação da Metafísica dos Costumes), CRPr (Crítica da Razão Prática), CFJ (Crítica da Faculdade do Juízo), Religião (A Religião nos Limites da Simples Razão), PP (À Paz Perpétua), M C (Metafísica dos Costumes), P M (Os Progressos da Metafísica), A P (Antropología Practica), LE (Lecciones de Ética), Ped. ( Sobre a Pedagogia). A indicação das traducães usadas, bem como as edições do texto em alemão consultadas se encontram ao final na bibliografia. 
rais. Sustento, portanto, que é possível, apesar das ambigüidades de Kant, pensar a imputabilidade moral a partir de recursos conceituais internos à Fundamentação. Desse modo, não será necessário invocar a distinção entre Wille e Willkür desenvolvida na $M C$, nem mesmo outras obras para dar conta deste problema.

Na $F M C$, Kant, ao pretender esclarecer o conceito positivo de liberdade, sustenta que

Como o conceito de uma causalidade traz consigo o de leis segundo o qual, por meio de uma coisa a que chamamos causa, tem de ser posta outra coisa que se chama efeito, assim a liberdade, se bem que não seja uma propriedade da vontade segundo leis naturais não é por isso desprovida de lei, mas tem antes de ser uma causalidade segundo leis imutáveis, ainda que de uma espécie particular; pois do contrário uma vontade livre seria um absurdo". (FMC III: $§ 2 /$ BA 97-98)

Com base nesta passagem, pode-se dar razão a Peter Rohs que considera Kant um causalista não fisicalista. Sendo causalista, Kant não deixa de considerar a liberdade "como uma certa estrutura causal" (1992: 171). Sendo um não fisicalista, ele distingue causalidade natural e causalidade por liberdade. Se temos de pensar a liberdade como a chave para o esclarecimento (Schlüssel zur Erklärung) do princípio moral, então não podemos renunciar à idéia de que uma ação livre tem de ser causalmente compreendida.

Todavia, há uma pergunta que deve ser feita, e ela é bem simples: por que uma ação não pode ser considerada um processo acausal? Isso significa perguntar sobre a possibilidade de entendermos a liberdade sem recorrer à noção de lei. Concede-se, assim, que causalidade implica legalidade e interroga-se se liberdade não pode ser apreendida como acausalidade, portanto, alegalidade. Esse questionamento atinge também a formulação de Kant sobre o caráter inteligível na $C R P$, visto que caráter era a lei da causalidade por liberdade. No entanto, embora Kant fale em lei da causalidade, que é o que permite que se tome o caráter como uma causa, na primeira Crítica a lei da causalidade por liberdade não recebe uma determinação conceitual precisa. Inclusive, como abono a essa interpretação, poderíamos recorrer a uma passagem na $C R P$ em que Kant fala em liberdade sem leis, a saber, em B 597 (“... an sich gesetzlosen Freiheit"). A expressão "liberdade sem leis" permite-nos apreender a liberdade como significando o início absolutamente espontâneo de um evento, a partir do querer de um sujeito, o qual agiria com liberdade justamente por realizar escolhas numa zona de inexistência de leis que determinassem a sua vontade. ${ }^{3}$

3 Também se encontra "liberdade sem leis" em CRP B 475, MC, $\$$ 42, 47 e 53, Religião, p.103 e A P, p. 83 e 85. No contexto em que Kant fala em liberdade extema ( $M C$, Religião e $A P$ ), deve-se observar que as 
Ora, uma coisa é, em sendo livre, ter o dever de seguir uma certa lei, outra é seguir uma lei, condição para ser livre. No questionamento presente visa-se tão-somente a verificar as razões em virtude das quais seria sem sentido conceber que, como o próprio Kant chegou a acreditar, "toda ação livre não está determinada nem pela natureza nem por lei alguma, sendo a liberdade algo espantoso, já que as ações não estão determinadas em absoluto" ( $L E$, Ak 258).

Alguém poderia, no entanto, considerar que o meu questionamento se debilita com a existência, no Cânon da $C R P$, de leis objetivas da liberdade (CRP B 830). Acredito que não existe obstáculo entre uma coisa e outra. Essas leis objetivas não impedem que se pense a liberdade sem elas. São leis morais (no contexto do Cânon) que não mantêm vínculo necessário com a liberdade. Poder-se-ia dizer que o vínculo é contingente, pois depende do uso que fazemos de nossa liberdade. É interessante, nesse propósito, uma passagem em B 837 onde encontramos uma referência à liberdade como sendo "em parte movida, em parte restringida por leis morais". É claro que pouco se poderia fazer com uma liberdade que só adquirisse sentido movida (bewegte) por leis morais. Entretanto, bem diferente é o caso de uma liberdade restringida (restringierte) por leis morais, ainda que "em parte"(teils). Nesse caso, a liberdade pode ser pensada como uma capacidade de ultrapassar os limites impostos pela moralidade, a qual visaria conter aquela espontaneidade absoluta ${ }^{4}$. Ainda mais interessante que essa passagem da $C R P$ é o que se pode ler na $F M C$. Na II seção, § 54 Kant diz que o "princípio da humanidade e de toda a natureza racional em geral como fim em si mesma" é "a condição suprema que limita a liberdade das ações de cada homem (oberste einschränkende Bedingung der Freiheit der Handlungen eines jeden Menschen ist)" (BA 69-70 - grifei).

leis em relação as quais a liberdade está desprovida são leis extemas, o que não autoriza, portanto, uma identificação direta dessas passagens com as acima tratadas da CRP. Contudo, se considerarmos que a minha liberdade extema "é a autorização de não obedecer a nenhuma lei exterior a não ser àquelas a que pude dar meu assentimento" ( $P$ P, Ak 350, n.), temos de admitir que a sua carência de leis também é carência de leis intemas, o que permitiria aproximar tais passagens daquelas da primeira crítica.

4 Poder-se-ia fazer uma aproximação desta passagem da CRP com a referência feita por Kant na Doutrina do Direito acerca de "um determinado uso da liberdade" (ein gewiser gebrauch der Freiheit) (M C Ak 231) que se toma "um dostáculo à liberdade segundo leis universais (isto é, contrário ao direito (umrecht) " (ib). Embora se trate, no contexto, de uma questão do direito, o uso da liberdade conflitante com a legalidade universal requerida como condição para a coexistência da liberdade de todos, apresenta-se como pertinente ao nosso problema. Se, como quer Kant, "tomar como máxima o agir conforme ao direito é uma exigência que me faz a ética" ( $M C$ Ak 231), então pode se considerar nesse caso o dever ser movido por leis morais. Este dever encontra resistências não simplesmente nos impulsos sensíveis, mas num certo uso da liberdade o qual deve ser restringido. Na moral esta restrição é intema. No direito, a restrição se dá mediante uma coerção. Encontramos também nas $L E$ compreensão similar acerca do uso da liberdade, segundo a qual quem atua contra o dever faz "um uso impróprio da liberdade" ( $L E$ Ak 289). Kant ainda afirma, na seqüência, não sem deixar de causar um certo desconcerto, que "agir contra o dever contém uma maior liberdade" ( 1) ) (Esta seria a razão para a imputação legal das conseqüências do uso impróprio da liberdade. Todavia, antes, na página 68, líamos: "A liberdade aumenta com o grau de moralidade") . 
Pois bem, a liberdade é a propriedade da vontade através da qual esta pode ser eficiente. Kant pretende esclarecer este enunciado buscando o conceito positivo de liberdade. Nesta busca, anuncia-se a carência de sentido de uma liberdade desprovida de leis. Um passo para entender isso pode ser dado se conseguirmos responder positivamente a uma pergunta básica: O que significa a expressão "vontade livre" (freie Wille)? Se "a vontade é, em todas as ações, uma lei para si mesma" (FMC III: § 2/BA 98), então a vontade é livre. Logo, uma vontade livre é uma vontade autônoma. Isso quer dizer que ela, sendo lei para si mesma, não adota senão uma máxima que pode "ter-se a si mesma por objeto como lei universal. Isto, porém, é precisamente a fórmula do imperativo categórico e o princípio da moralidade; assim pois, vontade livre e vontade submetida a leis morais são uma e a mesma coisa" (Ib.).

Esta última afirmação de Kant, em especial, é à primeira vista desconcertante. Pois se percebe claramente que não se trata apenas de ligar liberdade à lei, isto é, a alguma lei que não a natural, mas de ligar liberdade à lei moral. ${ }^{5}$ Ora, não é nem um pouco óbvio que uma vontade livre seja sinônimo de uma vontade moral. Kant se expõe a uma objeção muito simples: se uma vontade livre implica necessariamente o cumprimento da lei moral, concluise então que alguém que não segue a lei moral é portador de vontade não livre e, assim, não poderia ser lhe imputada a responsabilidade por uma ação contrária à moralidade. Realmente, se se iguala liberdade e moralidade, parece ser necessário admitir, como afirma Ferdinand Alquié, que "nós não somos mais livres desde que nós não somos mais morais e que nós não somos mais responsáveis por nossas faltas". ${ }^{6}$

Assim sendo, cumpre tentar perceber como Kant pode evitar uma tal objeção a qual, se de fato atingisse o seu argumento, seria uma objeção muito forte. Trata-se, portanto, de entender as razões que levaram Kant a defender tal posição. Mas, antes disso, é interessante observar uma outra conseqüência que se poderia extrair da tese kantiana.

O que Kant está sustentando se choca também com a concepção segundo a qual nós, não tendo acesso cognitivo ao caráter inteligível do agente, esta-

5 A tese da sinonímia encontra-se também formulada claramente na CRPr, em A 51,52 e A 167. Contudo, limito minha atenção, aqui, apenas na FMC.

6 Ferdinand Alquié (s/d: 96). Sobre esta dificuldade na filosofia moral de Kant, vale citar Valério Rohden. Fle afirma que "não fica esclarecido em que sentido a razão pode servir de fundamento a um poder subjetivamente a-legal; do mesmo modo não se entende à primeira vista por que uma tal liberdade, por não proceder segundo leis dbjetivas da razão, seja um jogo das inclinaçães, que caia necessariamente sob as leis da natureza" (1981: 133). Gostaria, ainda, de fazer referência a Ralph Walker. En seu artigo "Kant tem uma filosofia moral?" (1989), Walker, atento ao § 2 da III Seção, questiona a sinonímia ente agente livre e agente govemado pela lei moral, pois segundo ele "isso teria a absurda conseqüência de que um agente propriamente livre não poderia agir moralmente; nenhum ato imoral seria livre e, por isso, ninguém nunca seria responsável por uma ação errada" (1989: 16). Veja também em Ralph Walker (1982: 147) e H. Hudson. (1991). 
mos impossibilitados de saber se sua ação é livre ou não. Esta tese é enunciada literalmente na $C R P$ e estabelece que é imperscrutável se uma ação resulta do "efeito puro da liberdade" ou das determinações da "simples natureza, do defeito de temperamento" ou da natureza feliz (cf. B 579, n.). Porém, agora na $F M C$, Kant parece querer oferecer uma outra leitura do imperscrutável no domínio da moralidade. A sinonímia entre liberdade e moralidade não atinge a insondabilidade dos atos morais. Está de pé a afirmação de Kant de que "mesmo pelo exame mais esforçado, nunca podemos penetrar completamente até os móbiles secretos dos nossos atos, porque quando se fala de valor moral, não é das ações visíveis que se trata, mas dos seus princípios íntimos que se não vêem" (FMC II: § 2/BA 26). A insondabilidade que parece ser atingida pela sinonímia é justamente aquela destacada na primeira Crítica. Pois, embora não saibamos senão que uma ação é realizada conforme ao dever ou contrária ao dever, podemos saber, é o que se depreende da citação em pauta da III seção, que, sendo contrária ao dever, ela não é livre.

Pode-se distinguir no $\S 2$ da III seção duas teses não necessariamente vinculadas. Uma, mais acessível, diz respeito ao absurdo de uma vontade não governada por leis (que não leis da natureza). A outra, mais arrojada, se estriba no entendimento segundo o qual uma vontade livre não é governada senão por leis morais. A primeira tese deixa em aberto a possibilidade de candidaturas não obrigatoriamente morais à lei que governará a vontade. Ela veta apenas a candidatura das leis naturais. Na segunda tese se tem o pleito previamente decidido: existe apenas uma candidatura viável que se chama lei moral. Dessa forma, vale proceder a uma divisão na análise do nosso problema em dois momentos. À tarefa inicial cabe perceber melhor os laços entre vontade e lei. Para a segunda, cumpre verificar porque o pleito tem de ser com candidato único.

\section{Vontade e Lei}

O esclarecimento para esta questão se encontra, ao meu ver, na II seção da $F M C$. No início do $\S 12$, em que Kant faz uma espécie de introdução aos imperativos, se lê a conhecida passagem:

Tudo na natureza age segundo leis. Só um ser racional tem a capacidade de agir segundo a representação das leis, isto é, segundo princípios, ou: só ele tem uma vontade. Como para derivar as ações das leis é necessária a razão, a vontade não é outra coisa senão razão prática (FMC II: § 12/BA 36). ${ }^{7}$

7 Também em $F M C$, II, § 46, 134 / BA 63: "A vontade é concebida como a faculdade de se determinar a si mesma a agir em conformidade com a representação de certas leis". 
Esta passagem mostra, em primeiro lugar, a posição sempre clara de Kant acerca da legalidade da natureza, isto é, de que todo fenômeno está submetido à necessidade das leis da natureza. Na natureza tudo se "comporta" segundo uma constância estritamente determinada. Mas este trecho mostra também - e é isso naturalmente o que mais interessa aqui — que, não obstante a determinação necessária do que ocorre na natureza, a peculiaridade de um ser racional permite-nos ir além do necessitarismo do nach Gesetzen (segundo leis). É possível conceber um "agir segundo a representação das leis" ( nach der Vorstellung der Gesetze), o que significa pensar em uma capacidade de agir segundo princípios (nach Prinzipen). Concebido isso, pode-se nomear tal capacidade de vontade (Wille), atribuindo-a exclusivamente a um ser racional.

Visto que o que interessa aqui entender é a relação entre vontade e lei, a pergunta inicial que deve ser dirigida a Kant em relação a passagem em tela diz respeito ao sentido do termo "lei". Se "leis" significarem leis morais, então será inevitável a ociosidade de nossa tentativa acima apresentada de distinguir duas teses não necessariamente conexas acerca do caráter legal da vontade no início da III seção. Naturalmente, se vontade significar a capacidade de agir segundo a representação de leis morais, a vontade não poderá ser outra coisa senão rigorosamente vontade moral. Agora, se o sentido de "leis" significar princípios não apenas morais, mas também prudenciais e técnicos, a ligação entre vontade e lei não conduz diretamente a sinonímia vontade livre e vontade moral.

Convém deixar claro que está se tomando o termo vontade, quando não adjetivada, como vontade livre, pois do contrário, a distinção que confere nota característica à vontade seria inconsistente. Ou seja, uma vontade não livre não poderia significar a capacidade de agir segundo a representação de leis, pois não sendo livre, esta "vontade" deveria inserir-se na natureza em que tudo ocorre "segundo leis". ${ }^{8}$ Presumivelmente, não está imune a estas considerações a noção de razão prática. Na medida em que se distinguir vontade de vontade moral, se poderá perceber a distinção entre razão prática e razão pura prática. ${ }^{9}$ Por ora, procuro justificar a interpretação segundo a qual Kant quer significar neste contexto por "leis", não leis morais e, portanto, que vontade submetida à lei moral não abrange toda a extensão de vontade.

Pois bem, o que se depreende da seqüência do argumento de Kant no $\S$

8 É incontomável a dificuldade que essa argumentação coloca para o conceito de vontade heterônoma. 0 tratamento desse ponto será feito adiante.

Alquié (s/d: 37) : "A vontade ... é inseparável da razão, ela é a razão prática. Mas a razão prática não deve ser confundida com a razão moral que é a razão pura prática. Ela compreende também uma razão técnica ou empiricamente prática". 
12 parece confirmar a leitura a que estou visando. Kant se refere a uma determinação infalível da vontade pela razão e uma determinação não suficiente em relação a uma vontade não plenamente conforme à razão. No primeiro caso, certamente não se trata da vontade humana, pois o que se requer é que as ações resultantes da referida determinação sejam não apenas objetivas, mas também subjetivamente necessárias. Assim, a vontade não estaria sujeita, como no homem, a condições subjetivas. Portanto, é a segunda forma de determinação que concerne aos homens. Ocorre que, nesse caso, sendo as ações conhecidas como objetivamente necessárias e subjetivamente contingentes, para se conceber que a vontade se conforme às leis objetivas determinadas pela razão, é preciso recorrer à noção de obrigação (Nötigung). Ora, a obrigação estabelece uma relação entre vontade não absolutamente boa ${ }^{10} \mathrm{e}$ determinação da razão, isto é, entre uma vontade não totalmente perfeita do ponto de vista racional e representações de princípios objetivos emanados da razão. Estes princípios objetivos chamam-se mandamentos da razão, enquanto obrigam uma vontade, e imperativos, enquanto fórmulas dos mandamentos (Cf. FMC II: § 13/BA 37). Como se sabe, os imperativos podem ser hipotéticos (técnicos e pragmáticos) e categóricos. Logo, a vontade a que se refere Kant não pode ser vontade moral, porquanto ela não diz respeito apenas ao imperativo da moralidade. Dessa forma, as leis que a vontade representa incluem imperativos não morais.

Ciente de que essa não é uma leitura pacífica do texto kantiano, sou obrigado a examinar mais de perto o sentido de lei prática. $O$ caráter não pacífico da leitura pode ser demonstrado através da seguinte afirmação de Kant: "só o imperativo categórico tem o caráter de uma lei prática, ao passo que todos os outros se podem chamar em verdade princípios da vontade mas não leis" (FMC II: § 27/BA 49-50)" . A lei prática é o "princípio objetivo, válido para todo o ser racional, princípio segundo o qual ele deve agir, quer dizer um imperativo", diferentemente de uma máxima que "determina a razão em conformidade com as condições do sujeito" - sendo, "portanto o princípio segundo o qual ele age" (FMC II: $\S 30$, n./BA 51) $)^{12}$. Assim, parece razoável considerar que a palavra "imperativo" que entra na definição de lei prática se refere apenas a imperativo

10 Kant fala no final do $\$ 12 \mathrm{em}$ einem nicht durchaus guten Willen, sugerindo que uma vontade inteiramente boa seria sinônimo de uma vontade perfeitamente boa (ein vollkormen guter Willle). Porém deve-se observar que, nos $\S \S 75$ e 88 da II Seção (BA 81 e 95), quando Kant escreve schllechterdings gute Wille, ele não está se referindo senão à vontade dos homens, carente de máximas universalizáveis. Portanto, poder-se-ia dizer que os homens podem ter uma vontade absolutamente boa, mas não perfeitamente boa.

11 Conforme também em FMC II: §46/BA 64.

12 Cf. também em FMC I: § 15, n./ BA 15. Aí Kant contrapõe máxima à lei prática atribuindo à primeira o predicado de "princípio subjetivo do querer" e à segunda "princípio dbjetivo" do querer. É interessante que está é a mesma definição dada a motivo (Bewegungsgrund) em FMC II: §46/BA 63. 
categórico. Deve-se observar, contudo, que o problema não está, ao contrário do que quer Kant, na antítese "deve agir" versus "age"13 , mas na oposição entre validade universal, objetiva, e validade meramente subjetiva, porque também pertence aos imperativos hipotéticos a idéia de dever. De fato, "todos os imperativos se exprimem pelo verbo dever (Sollen)" (FMC II: § 14/BA 37). Entretanto, parece que somente a um imperativo categórico podemos outorgar a característica de validade universal, por conseguinte de leis como pretende Kant no $§ 23$ da II seção (BA 43-44). Neste parágrafo é feita a opção de chamar os imperativos hipotéticos, em vez de leis, regras da destreza e conselhos da prudência. Contudo, pode ser objetado a essa linha de argumentação que a "lei prática" da qual fala Kant se refere também aos imperativos técnicos e prudenciais. É claro que isso, por um lado, me favoreceria, já que o meu objetivo é interpretar a vontade como uma capacidade de agir segundo representação de leis não apenas morais - mas isso eu faço, por ora, amparado basicamente nos parágrafos 12 e 13. A presente questão, no entanto, coloca outros momentos do texto nos quais o comportamento do mesmo, considerado no conjunto, não é uniforme.

Que a lei prática valha também para imperativos hipotéticos é o que se pode depreender do $\S 14$ da II seção. Aí Kant argumenta que todos os imperativos impõem a prática do que é representado pela razão como bom. Ora, "praticamente bom é ... aquilo que determina a vontade ... não por causas subjetivas, mas objetivamente, quer dizer, por princípios que são válidos para todo ser racional como tal" ( $F M C$ II: $\S 14 / \mathrm{BA} 38)$. Portanto, as leis práticas teriam validade universal, a qual não seria, conseqüentemente, conferida apenas ao imperativo categórico, mas também ao imperativo hipotético. Isso provaria claramente uma hesitação de Kant com relação à noção de lei prática. Todavia, deixo esta vacilação de Kant em suspenso. O importante é perceber um outro ponto. Na verdade, a interpretação aqui proposta sobre o conceito de vontade em Kant requer a concessão às máximas o caráter também de leis práticas, em que pese o inevitável choque disso com certas passagens. ${ }^{14}$

Acredito ser mais produtivo concordar com Allison e Paton a esse respeito. Paton afirma que "de fato Kant define uma vontade como um poder

13 Beck, citando FMC BA 51, afima: "... Kant diz, de forma não totalmente precisa (not quite accurately), que leis determinam o que deve acontecer e máximas determinam o que acontece" (1966: 178). Grifo meu.

14 Além das passagens já referidas da FMC, ra CRPr, §1, Kant explicitamente distingue leis práticas de máximas a partir do caráter objetivo das primeiras em contraste com o caráter subjetivo das segundas (CF. CRPr A 36). Mas é digno de nota que Kant tenha também chamado máximas de leis. Por exemplo, na já referida passagem da CRP (B 834 e 840). Ainda nas $L E$ ena Pedagogia. Nas $L E$, Kant chama leis práticas de subjetivas ou objetivas, sendo as últimas pragmáticas ou morais ( $L E: 72)$. Pode-se ler ainda que "a máxima ... é uma lei subjetiva segundo a qual se age realmente" ( $L E$ : 81-82). Em SP: "Até as máximas são leis, mas subjetivas, elas derivam da própria inteligência do homem" (Ped. Ak 481). 
para determinar a si mesma a agir de acordo com a concepção de certas leis — isto é, de acordo com máximas" (1970: 82). Allison, por sua vez, considera que "...agir de acordo com a concepção de leis deve ser entendido como equivalente a agir com base em máximas (1990: 86).

Assim sendo, pode-se retomar a interpretação segundo a qual "representação das leis" não significa representação exclusiva de leis morais. Entretanto, se isso está razoavelmente assentado, um outro problema se coloca. Refiro-me à oscilação de Kant no $\S 12$ entre vontade como sinônimo de razão prática e vontade como faculdade de incidência das determinações da razão, portanto distinta da razão (a qual não pode ser senão razão prática). ${ }^{15}$ Quando Kant fala que os homens têm uma vontade em si não plenamente conforme à razão, poder-se-ia pensar numa dualidade da razão. Ou seja: uma razão não plenamente conforme à razão. Alguém talvez arriscasse a interpretação de que se trataria da razão prática não plenamente conforme à razão prática pura. Isso resultaria, porém, num dualismo da própria vontade: impura e pura. Talvez a alternativa mais rigorosa aqui seja perceber que o próprio conceito de vontade, neste contexto, não é preciso. A precisão se verificará na $M C$ através da distinção entre Wille e Willkür. A vontade já não é mais livre nem não livre. Ela é apenas a faculdade legisladora que dá a lei e é a lei para o arbítrio. Este sim, como faculdade executiva, escolhe seguir ou não a lei da vontade, sendo portanto livre. ${ }^{16}$ No entanto, como já afirmei, quero me restringir neste texto à $F M C$.

Pois bem, o que se conseguiu até aqui justifica plenamente a tese de Kant sobre o conteúdo legal da vontade. Realmente, uma vontade não governada por leis, isto é, uma vontade cujo sentido não fosse a capacidade de se determinar a si mesma a partir da representação de leis, simplesmente não seria uma vontade. ${ }^{17}$ Quer dizer, segue-se necessariamente da definição dada por Kant na II seção a afirmação no início da III seção de que a vontade sem leis é um absurdo. Portanto que a vontade deva ser em algum sentido governada por leis é, como afirmou Allison, "trivially true" (1990: 204), tendo em vista a exposição de Kant do agir racional (de um agir não segundo leis, mas conforme a representação das leis). Isto firmado, convém passar à tese da identificação entre vontade livre e vontade moral.

15 Em FMC I: § 7/BA 7, Kant afirma: "... a razão nos foi dada como faculdade prática, isto é, camo faculdade que deve exercer influência sobre a vontade." Nos §§ 14 e 15 da I seção (BA 14-15) ele também está supondo uma diferença entre razão e vontade.

16 đf. M C: Ak 226. Sobre esse ponto pode-se consultar: Allison (1990: 131), Zingano (s/d: 225-226), Patton (1970: 213-214).

$17 \mathrm{Na} C R P r$ se lê: "No conceito de uma vontade ... já está contido o conceito de causalidade" (A 96). Sendo que $\circ$ conceito de causalidade envolve lei, pode-se afirmar, com base na citação, que o conceito de vontade já traz consigo o de lei. 


\section{Vontade Livre e Vontade Moral}

Preliminarmente deve-se enfrentar uma interpretação defendida por $\mathrm{Pa}$ ton, segundo a qual é um equívoco pensar que Kant esteja no final do $\S 2$ defendendo que apenas uma vontade moralmente boa é livre, enquanto uma vontade moralmente má é determinada (ele quer dizer naturalmente determinada). A razão deste equívoco seria, por assim dizer, uma desatenção às palavras de Kant, porquanto não se está afirmando que uma vontade livre é uma vontade que sempre segue leis morais. Associada a essa desatenção ao texto estaria o esquecimento de uma lição da Crítica da Faculdade do Juizo. É esta segunda falha a razão, enfatizada por Paton, que mostraria o erro da leitura. Amparado no § 87, B 422, nota, da terceira Crítica, diz Paton: "Kant expressamente distingue entre uma vontade sob leis morais (under moral laws) e uma vontade que sempre obedece as leis morais (which always obeys moral laws)" (1970: 213).

Realmente, Paton toca num ponto que merece atenção. Talvez "vontade livre e vontade submetida a leis morais" não sejam sinônimas no sentido de que uma vontade livre é uma vontade moral e, portanto, quando falarmos de sinonímia teremos de mostrá-la em outro lugar. A opção de Paulo Quintella de traduzir unter sittlichen Gesetzen por "submetida a leis morais" (grifei) ${ }^{18}$ parece ajudar na confusão que Paton quer afastar. Falar em "vontade sob leis morais" parece resultar numa atenuação do peso da lei moral sobre a vontade. Porém o problema não reside aí. Em que pese as palavras "submetida" e "sob" poderem comportar uma semântica não idêntica, a alternativa de Paton não se deixa afastar por isso. O que cumpre ser analisado é se a proposta de Paton resolve a questão sobre saber se o vínculo entre liberdade e moralidade na $F M C$ significa que a liberdade é condição necessária e suficiente para moralidade. Paton tem, de fato, razão em querer impedir que se confunda uma vontade unter moralischen Gesetzen e uma vontade nach moralischen Gesetzen (CFJ: B 422, n). Mas, a rigor, a questão não é esta. O que realmente se exige é uma autorização baseada no texto da Fundamentação. Assim, as minhas pretensões neste caso são mais limitadas. A interpelação que se dirige a Kant em nenhum momento quer sugerir que Kant pudesse responder a ela sustentando que nós não somos responsáveis por nossas faltas ou que atos

18 Na tradução de Victor Delbos: "samisse à des lois morales" (I. Kant. Foumdements de la Métaphysique des Moeurs. Paris, Delagrave, 1920, p. 180). Paton, naturalmente, expõe menos esse problema em sua tradução da Fundamentação. Da mesma forma Beck. Ambos traduzem "unter sittlichen Gesetzen" por "under moral laws" (I. Kant. Groundwork of the Metaphysics of Morals. Tradução de H. J. Paton. New York, Hanper and Row, 1964, p. 114; I. Kant. Foundations of the Metaphysic of Morals. Tradução de Lewis White Beck. Indianápolis. The BobbsMerril, 1959, p. 65). Un̉a autra tradução para o português, de Antônio Pinto de Carvalho, traduz "unter" por "sujeita" (I. Kant. Fundamentação da Metafísica dos Costumes. São Paulo, Cia Ed. Nacional, 1964, p. 112) . 
imorais não são livres. O objetivo que tenho em vista é tão-somente verificar o comportamento do texto kantiano, especificamente da FMC. Ora, ao meu ver, o comportamento do $\S 2$ da III seção não autoriza a leitura de Paton ${ }^{19}$. Neste parágrafo, Kant entende por "vontade submetida a leis morais" uma vontade cuja causalidade é "segundo leis imutáveis", e mais precisamente uma vontade autônoma. Portanto, não se poderia dizer que é ambígua a expressão "vontade submetida a leis morais". Uma causalidade "segundo leis imutáveis" sugere uma causalidade segundo leis morais. Não vejo como se possa discordar, nesse caso, de Henry Sidwick que afirma, em comentário a esse ponto, que "uma vontade sujeita à sua própria lei moral pode significar uma vontade que, considerada como livre, conforma-se a estas leis; mas ela pode também ser concebida como capaz de livremente desobedecer estas leis - exercendo uma liberdade neutra. Mas quando a liberdade é tomada como uma "causalidade de acordo com leis imutáveis" a ambigüidade é dissipada. Pois isto evidentemente não pode significar meramente uma faculdade que determina leis que podem ou não ser obedecidas; isto tem de significar que a vontade, qua livre, age de acordo com estas leis (1966: 514-515). Realmente, seria difícil entender, em Kant, leis práticas não morais como imutáveis (Unwandelbaren). Mas se houvesse alguma dúvida sobre isso, bastaria olhar algumas linhas abaixo e ver que a liberdade da vontade é igual a autonomia e autonomia, diz Kant no mesmo parágrafo, admite apenas máximas morais. Portanto, o recurso à Crítica da Faculdade do Juízo não vale para entender o argumento de Kant na Fundamentação.

Mas Paton também menciona uma passagem da III seção em abono à sua leitura. No trecho mencionado, Kant afirma que somos responsáveis, não porque temos apetites e inclinações, mas sim pela complacência (Nachsicht) que podemos ter se concedermo-lhes influência (aos apetites e inclinações) sobre as máximas da vontade, prejudicando, dessa forma, as máximas racionais (Cf. FMC III: § 26/BA 118). Parece-me que, a partir dessa passagem, deve-se impor uma questão que não foi considerada por Paton. Refiro-me ao seguinte: qual a conseqüência dessa observação de Kant em relação ao seu argumento no $\S 2$ da III seção? Quero sustentar que, na verdade, Kant só vai extrair todas as conseqüências dessa passagem na Religião. Nesta obra, em que Kant elabora a doutrina do "mal radical" temos claramente uma exposição que confere liberdade ao homem que se afasta da lei moral através da recepção em sua máxima do princípio do amor próprio (Religião I: 34-45). Porém, com respeito à $F M C$ III: $\S 2$, o que se lê na passagem indicada por

19 Para Valério Rohden, "Paton não oferece uma resposta clara e satisfatória sobre o fundamento dessa distinção [AP: vontade sob leis morais e vontade que sempre obedece a leis morais]" (1981: 42) . 
Paton parece não passar de uma declaração verbal da qual não se percebe a incidência na tese do $\S 2$. Se Kant quer, como se depreende de BA 118, sustentar que a simples existência em nós de apetites e inclinações não nos torna maus, porém o que afeta a nossa moralidade é a indulgência na conversão dos móbiles sensíveis em máximas para ação, então, pergunto, poderíamos dizer que essa complacência é ato de uma vontade livre? Caso se responda afirmativamente, o que se segue é a incompatibilidade com a identificação entre vontade livre e vontade autônoma, pois não caberiam dúvidas de que uma tal complacência é sinal de heteronomia. Agora, se respondermos não, o resultado será dizer que, mesmo não sendo livres somos responsáveis, o que parece indefensável.

Dessa forma, acredito invalidar a interpretação de Paton sobre o $§ 2$ ao mostrar as dificuldades que derivam da aceitação de sua leitura.

É preciso reconhecer que o $\S 2$ da III seção está afirmando mais do que a autonomia como fundamento da moralidade. O que se lê é que a autonomia da vontade é um conceito que tem igual extensão que a liberdade. Assim sendo, é oportuno examinar como ficaria a situação da vontade heterônoma.

Se se aceita que ou a causalidade é natural ou é causalidade segundo leis morais, só sendo possível, portanto, necessidade natural ou autonomia, sucumbe-se ao problema da imputabilidade. Realmente, desde que na natureza tudo ocorre, incluindo aí, obviamente, as ações humanas, segundo uma conexão causal em que um efeito " $Y$ " é resultado necessário de uma causa " $X$ ", a qual por sua vez depende de outra causa, e assim sucessivamente, não se pode tomar tal modelo de causalidade como base para a imputação moral. O problema é que aí os eventos não são iniciados espontaneamente, mas são necessários desdobramentos, em última instância, físicos. Logo, inexistindo a possibilidade de se conceber um agente atuando livremente, a natureza não pode servir como recurso a quem se interessa pela responsabilidade moral. Restam, assim, os processos causais por liberdade. Mas, tendo em vista o modo como Kant está entendendo a liberdade no § 2, aí também não se pode imputar. Na verdade, não há o que imputar se só é livre quem age moralmente. No domínio da liberdade só existiria ações dignas de louvor. No domínio da natureza, encontrar-se-iam ações reprováveis, mas não se poderia legitimamente censurar os agentes, uma vez que estes não seriam livres, Naturalmente que Kant julgaria uma tal compreensão insustentável. Contudo, ao meu ver, Kant deveria ter esclarecido melhor a noção de heteronomia, porque a alternativa que entendo resolver a dificuldade da sinonímia reside em destacar a liberdade de uma vontade heterônoma, o que o próprio texto da Fundamentação - é o que quero mostrar - permite fazer.

Quando se lê que "a necessidade natural era uma heteronomia das causas 
eficientes" (FMC, III: § 2/BA 98) e se percebe tese semelhante na identificação entre heteronomia e leis naturais em FMC III: § 14/BA 109, é necessário perguntar se cabe ligar a noção de heteronomia, que diz respeito à vontade, com a legalidade natural. Com relação a primeira passagem poder-se-ia alegar em favor de Kant que do fato de toda necessidade natural ser uma heteronomia não segue que toda heteronomia é uma necessidade natural. Quer dizer, seria possível alegar que a heteronomia da vontade não é uma necessidade natural. Assim, pode-se considerar precipitada a posição de Peter Rohs, uma vez que ele considera ter Kant errado ao sustentar que a necessidade natural seria uma heteronomia das causas eficientes (1992: 18).

Todavia, a segunda passagem (FMC III: § 14/BA 109) coloca Kant numa situação difícil ${ }^{20}$ Seria necessário, como tentei mostrar acima, uma concepção "demasiado esquemática e simplista" ${ }^{21}$ pensar apenas em termos de uma disjunção exaustiva do tipo causalidade natural $=$ heteronomia ou liberdade $=$ autonomia $^{22}$. Desse modo, o que Kant revela parece ser uma assimilação da heteronomia da vontade com o arbitrium brutum tal como definido na CRP. Ora, isso seria insustentável se Kant quer manter a idéia de que os seres humanos não são patologicamente necessitados, mas apenas patologicamente afetados. Embora a afecção por móveis sensíveis seja uma condição necessária para se entender o arbítrio humano, ela não é uma condição suficiente.

Conforme Paton, e nesse ponto ele é mais cauteloso, Kant usa, conscientemente ou não, o termo heteronomia em dois sentidos.

Heteronomia no caso de objetos inanimados significa que suas ações causais são completamente determinadas a partir de fora. Este não é o caso se considerarmos a ação humana do ponto de vista do agente. Em todas as ações humanas a vontade é ativa e espontânea; ela de fato não age por causa da lei como tal, exceto no caso das ações moralmente boas, mas isto significa ir além de si mesma e a procurar a lei para determiná-la no caráter de algum outro objeto (1970: 215).

O que Paton está afirmando é importante para o presente contexto de discussão. É claro que a importância não está na sua, por assim dizer, complacência com Kant (ele parece querer, neste ponto, zelar pelo texto kantiano,

20 Que Kant fica numa situação dificill, eis aí um fato adnitido até por um comentarista extremamente simpático à causa kantiana como Allison (1995). Fle reconhece que, particularmente na FMC, Kant tende a equiparar heteronomia com sujeição às leis da natureza (1995: 304). No entanto, Allison acredita numa resolução muito simples dessa dificuldade. Ella pode ser resolvida se percebermos que a sujeição da vontade heterônana às leis da natureza significa simplesmente que as "inclinaçães e desejos sob as quais está baseada a escolha são produtos da natureza" (1995: 304-305), não se seguindo disso que a própria escolha é um produto da natureza.

21 Nesse ponto estou de acordo com Rohs (1992: 18).

22 Deve-se reconhecer que os imperativos hipotéticos e a heteronomia podem ser explicados pelo causalismo natural. Se fosse somente esse o ponto, Kant teria toda a razão. Acontece que o problema está na justificação de um juízo de imputabilidade de ações de uma vontade heterônoma. 
deixando de criticar sua ambigüidade), ${ }^{23}$ mas sim na indicação de um sentido produtivo de heteronomia presente na Fundamentação (Paton cita como abono FMC II: § 80/BA 88). Deve-se, portanto, ver o que Kant está aí afirmando sobre a heteronomia da vontade.

Em FMC II $\S 80 /$ BA 88, a heteronomia significa uma vontade cuja lei não é por si mesma dada, mas sim pelo objeto através de sua relação com a vontade. Segundo Kant, esta "relação, quer assente na inclinação, quer em representações da razão, só pode tornar possíveis imperativos hipotéticos". Aqui interessa reter que uma vontade heterônoma segue uma lei dada por um objeto através da relação entre este e a vontade, relação baseada ou na inclinação ou em representações da razão. Ora, uma inclinação (Neigung) é "dependência em que a faculdade de desejar está em face das sensações" ( $F M C$ II: § 24, n. /BA 39). Esta dependência (Abhängigkeit) não pode querer dizer que a faculdade de desejar seja patologicamente necessitada. É melhor compreender esta dependência no sentido em que Kant fala, na mesma passagem citada, de uma vontade dependente (abhängigen Willen), a qual tem o significado de uma vontade "que não é por si mesma em todo o tempo conforme à razão", diferentemente de uma vontade divina. Poder-se-ia, assim, conceber a relação entre vontade e inclinação sem retirarmos a espontaneidade da primeira. ${ }^{24}$ Se isso é razoável com respeito ao conceito de inclinação, muito mais tranqüila é a situação do conceito de representação da razão. É suficiente, neste caso, reportar-se ao que em páginas anteriores foi ponderado quando da análise do $\S 12$ da II seção. Dessa forma, a heteronomia da vontade também comporta liberdade ${ }^{25}$. Decerto tal conclusão colide com o início da III seção. Porém julgo-a mais consistente, tendo em vista as dificuldade que a tese da sinonímia apresenta.

Este texto começou tentando entender as razões pelas quais Kant não poderia concordar com uma liberdade sem leis. Sustentei que a base dessa discordância está na compreensão kantiana do agir racional, quer dizer, do

23 Paton deveria ter notado que Kant está usando o termo heteronomia em relação à vontade também no sentido que ele refere apenas ao caso dos objetos inanimados. Além disso, Paton não é claro sobre a questão de se saber onde os animais, seres dotados de arbítrio bruto, devem ser classificados. Porque, se temos de um lado objetos inanimados e de outro vontade humana, não sabemos como situar o arbítrio meramente animal. Talvez se pudesse resolver essa dificuldade entendendo heteronomia exclusivamente em sua referencia à vontade. Assim, qualquer objeto da natureza, seja animado ou inanimado, é sem vontade, vale dizer, nem heterônomo e nem autônomo.

24 Em consonância com essa leitura também se encontra, ao meu ver, a noção de aus Neigung versus aus Pflidt dos §§ 9 a 12 da I seção (BA 9-13). Kant opõe aí um agir por dever de um agir por inclinação estabelecendo que apenas o primeiro é digno de valor moral. Ora, então quem agir por inclinação é merecedor de censura moral. Logo, ele poderia ter agido de forma diferente, o que permite atribuir-Ihe liberdade mesmo tendo a sua faculdade de desejar mantido uma relação de dependência em face das sensaçães.

25 Segundo Paton., "presumivelmente nós temos de conceder que nós mesmos somos livremente influenciados por leis heterônomas" (1970: 215, n.). 
agir segundo representação de leis, portanto, no próprio conceito de vontade. Com isso se impôs a admissão de que é um absurdo uma liberdade desprovida de leis, mas não se percebeu, neste estágio, que seja absurdo uma liberdade segundo leis não morais. Para entender então a aparente sinonímia de $F M C$ III: § 2, preliminarmente, confutei Paton. Por fim, foi desenvolvido um esforço para mostrar que heteronomia envolve liberdade. Por certo uma vontade moral (autônoma) é uma vontade livre, mas nem toda vontade livre é uma vontade autônoma. Acredito ter, assim, conseguido mostrar que Kant se expressa de um modo pouco feliz no $\S 2$ da III seção.

\section{Bibliografia}

ALLISON, H. (1995): "Morality and Freedom: Kant's Reciprocity Thesis". In: CHADFWICK, Ruth F. (org). Immanuel Kant's: critical Assessments. Vol. III. London e New York: Routledge, (reimpressão), p. 284-310)

ALLISON, Henry (1990): Kant's Theory of Freedom. New York, Cambridge University Press.

ALQUIÉ, Ferdinand (s/d): La Morale de Kant. Paris: CDU.

BECK, Lewis White (1966): A Commentary on Kant's Critique of pratical reason. Chicago: The University of Chicago Press.

HUDSON, H. (1991):"Whille, Willkür, and the Imputability of Immoral Actions". Kant Studien, 82 (2): 179-196.

KANT, Immanuel. Kritik der reinen Vernunft. Werkausgabe III/IV. Ed. W. Weischedel. Frankfurt, Suhrkamp, 1991.

. (CRP): Crítica da Razão Pura. Tradução de Valério Rohden e Udo Baldur Moosburguer. São Paulo, Abril Cultural, 1980.

- (LE): Lecciones de Ética. Tradução de Roberto Rodriguez Aramayo e Concha Roldan Panadero. Barcelona. Crítica, 1988.

. (AP): Antropología prática. Según el manuscrito inédito de C. C.Mrongovius, fechado en 1785. Edición preparada por Roberto Rodrigues Aramayo. Madrid, Tecnos, 1990.

. Grundlegung zur Metaphysik der Sitten, Werkausgabe VII. Ed. W. Weische-

del. Frankfurt, Surkamp, 1991

. (FMC): Fundamentação da Metafisica dos Costumes. Tradução de Paulo Quintela. São Paulo, Abril Cultural, 1980.

—. Fundamentação da Metafísica dos Costumes. Tradução de Antônio Pinto de Carvalho. São Paulo, Cia Ed. Nacional, 1964. Fondaments de la métaphysique des Moeurs. Trad. De Victor Delbos. Paris. Librairie Delagrave, 1920.

. Groundworks of the Metaphysics of Morals. Tradução de H. J. Paton. New York, Harper and Row, 1964.

. Foundations of the Metaphysic of Morals and What is Einlightenment?. 
Tradução de Lewis White Beck. Indianápolis: The Bobbs-Merril, 1959.

- Kritik der praktischen Vernunft. Werkausgabe VII. Ed. W. Weischedel. Frankfurt, Surkamp, 1991. 70, 1986. (CRPr): Crítica da Razão Prática. Tradução de Artur Morão. Lisboa, Ed. Kritik der Urteilskraft. Werkausgabe X. Ed. W. Weischeedel. Frankfurt am Main. Surhkamp, 1991.

. (CFJ): Crítica da Faculdade do Juízo. Tradução de Valério Rohden e Antonio Marques. Rio de Janeiro, Forense, 1993.

. Die Religion innerhalb der Grenzen der blossen Vernunft. Werkausgabe VIII. Ed. W. Weischedel. Frankfurt, Surkamp, 1991.

. (Rel.): A Religião nos limites da simples razão. Tradução de Artur Morão. Lisboa, Ed. 70, 1992.

—. (PP): À paz perpétua. Tradução de Marco A. Zingano. Porto Alegre: L\&PM, 1989.

Die Metaphysik der Sitten. Werkausgabe VIII. Ed. W. Weischedel. Frankfurt, Surkamp, 1991.

(MC): La Metafisica de las Costumbres. Tradução de Adela Cortina Orts e Jesus Conill Sancho. Madrid: Tecnos, 1994.

—. (Ped.): Sobre a Pedagogia. Tradução de Francisco Cock Fontanella. Piracicaba, Unimep, 1996.

$70,1985$.

PATON, H. J. (1970): The Categorical Imperative: A Study in Kant's Moral Philosophy. London, Hutchinson,

ROHDEN, Valério (1981): Interesse da Razão e Liberdade. São Paulo: Ática.

ROHS, Peter (1992): “Teoria Transcendental-filosófica da ação - um esboço". In: Rohden, Valério. (org). Racionalidade e Ação. Porto Alegre: UFRGS e Instituto Goethe.

SIDWICK, H. (1966): "The Kantian Conception of Free Will". In: The Methods of Ethics. New York. Dover Publication, Inc.

WALKER, Ralph (1982): Kant: the arguments of the Philosophers. London, Routledge and Kegal Paul.

WALKER, Ralph (1989): “Kant tem uma filosofia moral?" Filosofia Política, 5. p. 7-22.

ZINGANO, Marco (s/d): "Fait de la Raison et Acte de la Liberté chez Kant". In: L'Etat. Philosophie Morale et Politique. Tiré à part, les cahiers de Fontenay. 